\title{
The Impact of Cultural Events on Community Reputation and Pride in Maribor, The European Capital of Culture 2012
}

\author{
Suzana Žilič Fišer ${ }^{1}$ iD $\cdot$ Ines Kožuh ${ }^{1}$
}

Accepted: 28 June 2018 / Published online: 5 July 2018

(c) The Author(s) 2018

\begin{abstract}
This paper examines the cultural and social impacts of the European Capital of Culture (ECOC) on the case of the Slovenian city Maribor, the cultural capital of Europe in 2012. The aim is to examine whether geographical area, time, and the level of participation, affect the community reputation and community pride of the citizens. Collection of data occurred twice - at the halfway point, and at the end of the ECOC year-and was conducted on a sample of 2156 citizens from Maribor and 2635 citizens from whole country. The results revealed that, firstly, feelings of community reputation rose during the ECOC year. People from Maribor showed a stronger sense of community reputation than Slovenes. Secondly, people from Maribor were, at the halfway point of the ECOC year, prouder of the event than Slovenes, which changed by the end of the year. Generally, community pride of the ECOC designation improved till the end of the ECOC year, in Slovenes more than in people from Maribor. Thirdly, Slovenes who participated actively in the ECOC events had a higher sense of community reputation than the actively involved people from Maribor. By contrast, passively involved people from Maribor had a stronger sense of community reputation than passively involved Slovenes. The results led to suggestions to organisers of the ECOC events to be aware of the wide impact of the organised events on public opinion for community reputation and pride in a particular city and country.
\end{abstract}

Keywords Culture European Capital of Culture $\cdot$ Community reputation · Community pride $\cdot$ Participation

\section{Introduction}

The European Capital of Culture (ECOC) is known as one of the most prestigious, attractive and popular cultural programmes in the European Union. It involves numerous cultural events each year in public places in certain cities, and tries to reach a wide audience, to increase awareness and participation in culture. The programme has become a key platform

Suzana Žilič Fišer

suzana.zilicfiser@um.si

1 Faculty of Electrical Engineering and Computer Science, Institute of Media Communications, University of Maribor, Maribor, Slovenia 
for city positioning and a catalyst for economic and cultural regeneration (Garcia and Cox 2013).

However, besides common approaches and strategies of the ECOC cities, there are peculiarities of the ECOC model for each city. These peculiarities are either political decisions affecting implementation of the ECOC programme, or socio-cultural effects of the ECOC implementation. Firstly, from the political point of view, the European Commission released a political decision in 2017 that, due to the Brexit, the UK cities could not participate in the selection process for ECOC in 2023. This may influence the cultural sector across Europe importantly, especially due to the widely recognised socio-cultural influence of ECOC on the broader community.

Secondly, existing literature addressed the socio-cultural effects of the ECOC implementation on community advantageously. For instance, Liu (2014), revealed in the case of Liverpool 2008, an impact in terms of improved residents' sense of place and pride, enhanced quality of life, as well as accessibility and the inclusion effect of cultural events for residents. These were found to remain sustainable even eight years after the ECOC implementation (Liu 2017a, b). Similarly, previous studies (Richards and Wilson 2004; Hudec and Džupka 2014) focused on the impact of ECOC events on city image in terms of enhancement of community pride and citizens' opinions about the city. Moreover, Garcia (2005), examined the long-term impact of the ECOC held in Glasgow in 1990 in terms of Glasgow's image and identity resulting from media and personal discourse. Likewise, Lähdesmäki (2014) analysed the discussions of European identity in the reception of the ECOC events in Pécs. In this vein, understanding public engagement and the impact on individuals and communities in terms of local perceptions of the ECOC were examined as well (Garcia 2010; Davies 2012; as cited in Garcia and Cox 2013).

Combining both political and socio-cultural impacts has already been a subject of research, where the importance was examined of political meanings and practices in terms of understanding the ECOC as a multi-level policy at the European, national, regional and local levels (Palonen 2010). Moreover, it was discussed how applying foreign experiences in policy-making can intertwine with local initiatives (Lassur et al. 2010).

The above-mentioned socio-cultural effects were found to result in revived city streets and citizens' renewed pride in their home city (Richards and Wilson 2004). In literature, this is referred to as the 'halo effect' (Hall 1992), the 'showcase effect' (Fredline and Faulkner 1998) and the 'feel good effect' (Allen et al. 2002, as cited in Richards and Wilson 2004).

Therefore, the political, economic and artistic interest has been growing for ECOC in the last decade. For instance, not only the socio-cultural effects of ECOC were of interest to researchers, but the economic aspect has also been examined. Namely, positive ECOC impacts were found on infrastructure investment, financial budgets and tourism flows (Mittag 2008; Palmer 2004), as well as GDP per capita and GDP per capita growth in relation with life satisfaction (Steiner et al. 2015). In this regard, communication, branding and marketing strategies via a social semiotic critique of visual resources were examined, deployed in the official promotional texts of ECOCs (Aiello and Thurlow 2006).

Both economic and artistic success resulting from ECOC designation are frequently tightly connected to community reputation and pride, leading to increased interest for research of this issue. In this vein, the current paper discusses a particular case of the ECOC experience in the second largest Slovenian city, Maribor, which was the ECOC in 2012. The main objective is to provide insight into the effects of ECOC on community reputation and community pride while considering additional relevant factors, such as the time period within the ECOC year, geographical area and the level of the citizens' participation. 
Previous studies on the ECOC programme have examined the time effects of the ECOC advantageously on the one hand, and the impact of ECOC events on the image of the city (including community pride) on the other hand, where the visitor's origin was also considered (as a citizen of the ECOC city or other parts of the country). A problematic aspect of these studies, however, is that they disregard the concurrent effect of time factor and geographical area, as well as the time factor and the level of the citizens' participation. Time factor as a duration of the ECOC with the interdependent varying intensity of events, could have an impact on citizens' perception of community reputation and community pride. For instance, the effect may vary over time during the ECOC project, as pride and reputation can be experienced in one half of the ECOC year differently than at the end of the year. In addition, there may be a concurrent effect of participants' origin or geographical area, since the effect may differ together with the increasing distance from the central location of the ECOC events. Moreover, community reputation and community pride may depend on the level of citizens' participation. For instance, visitors who participated actively in ECOC events may experience a different level of pride or reputation in comparison with passive visitors.

In this regard, the main aim of our study was, firstly, to examine whether the duration of the ECOC within different time periods and geographical area, which is either confined narrowly to the ECOC city or the country as a whole, affects citizens' sense of community reputation and community pride. Secondly, our study aimed to examine the effects of citizens' participation in ECOC events and geographical area on community reputation and community pride. Moreover, effects of socio-demographic characteristics, such as gender, age and level of education in relation with geographical area, on community pride were observed.

\section{Background}

\subsection{The ECOC Programme, Community Reputation and Community Pride}

The beginning of the ECOC dates back to 1985 and, since that time, the event has been rotating among the European Union (EU) Member States; with one or two different cities hosting the ECOC each year (Richards and Wilson 2004). The aims of the ECOC hosting cities were to show their local or national culture to a European audience, and to create a picture of European culture as a whole (Corijn and Van Praet 1994).

Accordingly, in the literature, it has been recognised that ECOC events can arouse various personal feelings about the city among the visitors of these events. The ECOC was found to stimulate the change in the image of the city, which is experienced differently by various groups of visitors. For instance, with regard to the visitor's origins, citizens of Rotterdam, the ECOC holder city in 2001, were found to have a stronger and more positive image of their own city, and see Rotterdam as a big international city in comparison with other Dutch cities. In contrast, Dutch tourists from other parts of the country were found to have "a weaker, more diffuse image of the city as a whole" (Richards and Wilson 2004: 1946).

People's attachments to place are often intertwined with their sense of community (Garcia 2003), while communities are mostly defined geographically (Manzo and Perkins 2006). This convention is followed in this paper as well, where we have not confined ourselves to physical presence in a certain place, but rather broadened the scope of the 
understanding of participation by including passive ECOC visitors who were familiar with the ECOC events, but were not physically present at these events.

The communities have multiple identities, images and reputations that may change over time. Reputations typically consist of a skewed distribution of beliefs with a greater or lesser degree of conformity among members of a group. This is the result of the spread of information and influence in social networks (Bromley 2003). The community reputation can, therefore, be understood as a multifaceted issue, which includes sets of norms, beliefs and pieces of information which apply to the community within a certain period of time.

As the intention of the ECOC is to include different stakeholders in society, it could influence the fabric of communities where the project takes place. This can be connected further to social cohesion, where the formation of self and community identities is linked to memories, recollections and images of places (Aronowitz 1992; Crow 1994).

The issue of community pride and community reputation could be connected closely to the process of the cities where the urban dynamics and urban governance tackle the issues of social cohesion (Kearns and Forrest 2000), as societies are becoming more fragmented. Therefore, the desire for the ECOC designation as a community project may be connected closely to community perception and a desire for the coherent development of the community in the future. Accordingly, such community benefits are recognised mostly as a sub-factor of noneconomic (or social) benefits (Grieve and Sherry 2012). According to Delamere et al. (2001: 19), community benefits include the "celebration of community, enhancement of community identity, image and uniqueness, improved quality of life, pride and community recognition." However, the literature on community reputation and pride as community benefits is still limited, and is devoted mainly to the economic impacts of city engagements in the projects.

In order to be able to understand the ECOC as a local and national motivation element, it is necessary to understand how a particular community perceives it. Specifically, in Maribor, one of the characteristics of the used ECOC model was the hyper production of events that were not elite artistic events but, in many cases, community events, targeted at broader segments of society. Thanks in part to their being entrance fee free, it led to the increased participation of citizens. Since the ECOC title is also a brand recognised at an international level, from the citizens' perspective, it may be connected closely to citizens' pride and reputation on the national level. Maribor, the second largest city in Slovenia, applied for the ECOC title in 2007. The decision that Maribor, with partner cities, would be given the title, as the first time in Slovenia and first time in any country from ex-Yugoslavia, was also recognised as a political decision at the national level. Since Slovenia has no regional division, this decision could also be recognised as one step towards the regional development. The reason is that the East cohesion region was perceived as less developed, and there was evidently a need for additional economic development. Moreover, Maribor, well perceived as an industrial city in ex-Yugoslavia, lost its industrial identity when the greatest factories were closed soon after the independence of Slovenia. The driving force for the title was, thus, also the motivation for searching for a new identity for the city, identity based on the cultural production. However, the problem that caused many uncertainties of the project was the economic situation. In 2007, the economic forecast for the year 2012 when the ECOC would start in Maribor, differed somewhat from the economic reality in that year (Žilič Fišer and Erjavec 2017). Financial and infrastructural plans were not fulfilled, as the Municipality and the State were financing the project with smaller units of investments (28 mio from an expected 56 mio eur). Unfulfilled expectations of the cultural sector built the frustrations, and also caused the political difficulties. Additionally, for the Slovenian capital, Ljubljana, which also competed for the title but was not selected, it caused frustrations 
in the losing city. Even more, the rebellion against the activities of the actual Mayor in Maribor, caused the protests which happened at the end of 2012. This large movement on the local and national political level threw a shadow on cultural activities in the city. However, the pride and the reputation of the city was motivated, firstly, with the cultural events, but could also be spread towards the other fields of human actions (politics).

\subsection{The ECOC and Effects of Socio-demographic Characteristics}

Recent studies have examined extensively the effects of socio-demographic characteristics, such as gender (e.g. Bihagen and Katz-Gerro 2000; Seaman 2006; Stafford and Tripp 2000; Lähdesmäki 2012), age (e.g. Stafford and Tripp 2000; Boyle et al. 2010; Garcia and Cox 2013) and level of education (e.g. Garcia et al. 2010; Garcia and Cox 2013), on people's attitude towards ECOC and cultural events or culture in general.

Firstly, in terms of gender, women were found to participate more actively in cultural activities (Bihagen and Katz-Gerro 2000; Seaman 2006; Stafford and Tripp 2000). For instance, it was substantiated that more women than men participated at previous ECOC events in Turku (Turku 2011 2010; Turku 2011 Foundation 2012; cited in Garcia and Cox 2013) and Guimarăes 2012 (University of Minho 2013; cited in Garcia and Cox 2013). However, the share between male and female participants was equal in Luxembourg (Luxembourg and Greater region 2007 2008; cited in Garcia and Cox 2013).

Gender differences are obvious also in the attitude towards culture, ECOC and national cultural events. For instance, women consider concepts of locality, regionality and Europeanness more positively than men, while conversely, men consider national culture more positively than women. Women also recognised the above-mentioned concepts in the ECOC events more often than men, and tended to consider these events as representation of locality and Europeanness to a greater extent (Lähdesmäki 2012). Similarly, Richards and Wilson (2004) found that women are far more likely to agree that Rotterdam being designated for the ECOC holder city is a centre for culture, art and events related thereto than men.

Secondly, regarding age, middle-aged people were found to be the typical audiences of cultural activities (Stafford and Tripp 2000; cited in Lähdesmäki 2014), while large-scale urban festivals may attract younger visitors as well (Boyle et al. 2010; cited in Lähdesmäki 2014). For instance, the ECOC events held in Porto 2001 recorded a relatively young audience (33.4\% under 24) which is similar to Liverpool 2008, with $11 \%$ of its audience aged between 16 and 24, and Guimarăes 2012, with $20 \%$ of its audience at younger than 25 and 62\% under 44 (Palmer/Rae Associates 2004; University of Minho 2013; cited in Garcia and Cox 2013). Middle-aged audiences prevailed in Bruges 2002 (the largest proportion aged 25-54) and in Rotterdam 2001, with 55.4\% of the audience over 40 (Palmer/Rae Associates 2004; cited in Garcia and Cox 2013).

Thirdly, as far as education is concerned, Garcia and Cox (2013) argue that level of education of audiences and participants across different ECOCs is similar to that of occupation and income groups. Accordingly, the data on participants' occupation from past ECOC events in Porto 2001, Rotterdam 2001, Salamanca 2002 and Luxembourg 2008 revealed that an important proportion of audiences came from Director/Manager, professional or technical professional occupations, and, similarly, Liverpool 2008 recorded a smaller proportion of its audience from the lowest social and economic groups in the society (Palmer/ Rae Associates 2004; Luxembourg and Greater region 2007 2008; Garcia et al. 2010; cited in Garcia and Cox 2013; Richards and Wilson 2004; Richards 2000). Similarly, previous 
studies (Steiner et al. 2015; Richards and Wilson 2004) found on a sample of several ECOC holder cities that more highly educated individuals are more inclined to attend ECOC events more often. They also benefit from hosting ECOC more than those who have a low level of education and are, concurrently, unemployed. In particular, these individuals are confronted with noise, disturbance, congestion and higher prices. Consequently, during the year in which the ECOC was hosted, a negative impact on the individual life satisfaction was found (Steiner et al. 2015).

\subsection{Literature Shortcomings of the Effects Related to ECOC Programme}

From the existing literature on the ECOC programme, community reputation and community pride, it is still not clear whether the level of citizens' participation in ECOC events (when simultaneously considering citizens' geographical origins) affects the way they perceive the importance of the ECOC, both for the city and for the country as a whole. In addition, it has not yet been addressed how the time period and geographical area affect the reputation and pride of the community with regard to the ECOC designation. Due to the specifics of the ECOC models and programmes, which may vary between different ECOC holder cities and related national environments, it is, thus, relevant to examine community reputation and community pride in the context of the case of Maribor as an ECOC holder.

Moreover, the literature addressing effects of socio-demographic characteristics, such as gender, age and education, focused mainly on the question of which social groups are targeted or usually participate in the ECOC events. It was found that women do so more frequently than men, middle-aged, and the young population more frequently than older people, and more highly educated more frequently than less educated individuals. Also, the literature focused on the attitudes of the above-mentioned social groups towards the ECOC, where recognition of ECOC events as representation of locality and Europeanness was found to be biased in favour of women. Even though the above-mentioned sociodemographic characteristics were examined extensively in terms of effects related to ECOC, these characteristics have not yet been thoroughly examined in terms of effects on community pride of the ECOC designation in a particular city.

\section{Methodology}

The current paper is based on empirical data collected across Slovenia, with a population of 2,062,874 (Statistical Office of the Republic of Slovenia 2015), and, specifically, in Maribor, the second largest city in Slovenia, with a population of 95,586 (Statistical Office of the Republic of Slovenia 2014).

The data was collected during 2012 via the telephone-surveying technique ComputerAssisted Telephone Interviewing (CATI). The data collection occurred twice that year (the first time-period included the first half-year, and the second time-period followed) both in Maribor $(n=2156)$ and across the entire country $(n=2635)$. Our primary aim was to monitor the response to the activities of the Project Maribor-The European Capital of Culture 2012, which took place primarily in Maribor.

Table 1 shows the distribution of the samples for each time-period, where every time a new sample was recruited. Before taking part in the survey, participants had to agree to participate in the study voluntarily. Table 1 also shows a brief socio-demographic background of the respondents, which differed to some extent between the samples. 
Table 1 Basic characteristics of the samples

\begin{tabular}{|c|c|c|c|c|c|c|}
\hline \multirow{3}{*}{$\begin{array}{l}\text { Time period } \\
\text { Sample size }\end{array}$} & \multicolumn{3}{|l|}{ Maribor } & \multicolumn{3}{|l|}{ Slovenia } \\
\hline & 1 & 2 & Total & 1 & 2 & Total \\
\hline & $\mathrm{n}=787$ & $\mathrm{n}=1369$ & $\mathrm{n}=2156$ & $\mathrm{n}=1325$ & $\mathrm{n}=1310$ & $\mathrm{n}=2635$ \\
\hline \multicolumn{7}{|l|}{ Gender } \\
\hline Female & 428 & 720 & $1148(53 \%)$ & 703 & 701 & $1404(53 \%)$ \\
\hline Male & 359 & 649 & $1008(47 \%)$ & 622 & 609 & $1231(47 \%)$ \\
\hline \multicolumn{7}{|l|}{ Years } \\
\hline Mean & 50.28 & 48.62 & 49.22 & 49.57 & 51.02 & 50.29 \\
\hline SD & 18.65 & 17.56 & 17.98 & 17.77 & 17.37 & 17.58 \\
\hline \multicolumn{7}{|l|}{ Education } \\
\hline $\begin{array}{l}\text { Unfinished/finished } \\
\text { primary school }\end{array}$ & 165 & 200 & $365(17 \%)$ & 277 & 273 & $550(21 \%)$ \\
\hline Vocational school & 103 & 166 & $269(12 \%)$ & 206 & 194 & $400(15 \%)$ \\
\hline Secondary school & 310 & 611 & $921(43 \%)$ & 528 & 533 & $1061(40 \%)$ \\
\hline High school or more & 209 & 392 & $601(28 \%)$ & 314 & 310 & $624(24 \%)$ \\
\hline
\end{tabular}

However, our methodological approach has two main limitations. The first limitation is a lack of representativeness of the sample, since, due to the data collection method used, participation in the study was not fully accessible to the wider public. In particular, we left out people with no telephone land line, while also persons with hearing loss were excluded from the study (Debevc et al. 2015). The second limitation is that we cannot know exactly to what extent the reported data is accurate, and to what extent respondents actually were familiar with, and did participate in, ECOC events.

We used repeated cross-sectional telephone surveying, and the questionnaire consisted of several sections, measuring the following:

1. The level of spontaneous recall of the ECOC, where respondents were asked in one question to name the greatest cultural event being held in Maribor in 2012.

2. Assessment of the sense of the ECOC contribution to the reputation of Maribor and Slovenia, the encouragement of creativity, as well as community pride in Maribor. For the above-mentioned set of items respondents were asked: 'I will read you a set of statements and you should assess them on the scale from 1 to 5 to what extent you agree with each statement. One means that you disagree strongly with the statement and 5 means that you agree strongly with it.' Afterwards, for each of the above-mentioned items one statement was provided. Examples of the statements for contribution to the reputation of Maribor and Slovenia are: 'ECOC contributes to the reputation of Maribor.' and 'ECOC contributes to the reputation of Slovenia.' An example of the statement for community pride is: 'Maribor can be proud of being an ECOC.' Respondents could answer according to 5-point Likert-type questions, ranging from 'disagree strongly', 'disagree', to 'neither disagree nor agree' and 'agree' to 'agree strongly'.

3. Stimulated knowledge of the ECOC, or participation in the ECOC, where four questions were provided in which respondents were asked to express what they thought about when they heard about the Project ECOC Maribor 2012, how many and what types of events they had already attended, as well as the reasons for attending those events. 
4. Estimation of future presence at ECOC events, where respondents were asked with one question if and why they would or would not attend future ECOC events.

5. Assessment of ECOC events according to affordability (price), versatility/diversity and quality of the events; assessment of practicality of the whole ECOC project. Five questions were provided. An example: 'ECOC events are of a high quality.'

6. Information about ECOC events, where respondents were asked to estimate how they were informed about the events and what their source of information was. Two questions were provided.

7. Socio-demographic data about respondents (gender, age, level of education, employment status, number of members in a household and their income, region and type of settlement).

Descriptive statistics were utilised for the data analysis. Moreover, as we repeated our study twice on different samples within Maribor and Slovenia in terms of using the same survey every time, we conducted a repeated cross-sectional analysis (Firebaugh 1997). Accordingly, we measured statuses at two different time points, and changes in statuses, considering these time points for the particular samples. We used two-factor between-groups analysis of variance (ANOVA) where our primary purpose was to understand whether there is an interaction between the two independent variables on the dependent variable. The interaction term in this statistical test informs us whether the effect of one of the independent variables on the dependent variable is the same for all values of other independent variables (and vice versa) (Laerd Statistics 2015b).

To investigate further whether community pride can be predicted by particular sociodemographic characteristics, we employed multiple regression. In particular, we wanted to predict the value of a variable community pride based on the values of socio-demographic variables (gender, age and education) and a variable 'geographical area'. This statistical test allowed us to determine the overall fit (variance explained) of the particular model and the relative contribution of each of the predictors to the total variance explained (Laerd Statistics 2015a). As we wanted to see concurrently which demographic subgroups of the population were affected more or less strongly by geographical area when investigating community pride, we also employed interactions between the variable geographical area and other socio-demographic variables in the multiple regression analyses. In this approach, we followed the principles of the analysis by Steiner et al. (2015) where the difference-in-difference-estimations of the impact of an ECOC on individual life satisfaction were conducted.

All of the analyses were performed at the significance level of .05. The analyses were performed with the IBM SPSS Statistics 21.0 (IBM SPSS Statistics for Windows, Version 21.0 2018).

The time points in our study were selected in the year 2012, based on the ECOC events held in Maribor and Slovenia. The first time point was set after the first half-year, and the second time point was set after the second half-year. In this way, the impact of ECOC events could be studied, as was the case in a previous study (Weisberg et al. 1995) where the authors examined the impact of social events that occurred between the surveys. 
Table 2 Descriptive statistics of variables

\begin{tabular}{|c|c|c|c|c|c|c|c|c|c|c|c|c|}
\hline \multirow{3}{*}{$\begin{array}{l}\text { Geographical area } \\
\text { Time period }\end{array}$} & \multicolumn{6}{|c|}{ Maribor } & \multicolumn{6}{|c|}{ Slovenia } \\
\hline & \multicolumn{2}{|l|}{1} & \multicolumn{2}{|l|}{2} & \multicolumn{2}{|c|}{ Total } & \multicolumn{2}{|l|}{1} & \multicolumn{2}{|l|}{2} & \multicolumn{2}{|c|}{ Total } \\
\hline & M & SD & $\mathrm{M}$ & SD & M & SD & M & SD & M & SD & M & SD \\
\hline $\begin{array}{l}\text { (a) ECOC contribu- } \\
\text { tions to the reputa- } \\
\text { tion of Maribor }\end{array}$ & 3.87 & 1.08 & 3.95 & 1.06 & 3.92 & 1.07 & 3.66 & 1.05 & 3.80 & 1.03 & 3.73 & 1.04 \\
\hline $\begin{array}{l}\text { (b) ECOC contribu- } \\
\text { tions to the reputa- } \\
\text { tion of Slovenia }\end{array}$ & 3.59 & 1.21 & 3.54 & 1.18 & 3.56 & 1.20 & 3.60 & 1.11 & 3.60 & 1.10 & 3.60 & 1.11 \\
\hline (c) Community pride & 4.06 & 1.04 & 4.27 & 1.06 & 4.19 & 1.08 & 3.68 & .97 & 4.45 & .87 & 4.06 & 1.00 \\
\hline
\end{tabular}

Table 3 Results of effects of time period and geographical area on the ECOC contributions to the reputation of Maribor, Slovenia and community pride

\begin{tabular}{lccc}
\hline & $F$ & $p$ & $\eta_{p}^{2}$ \\
\hline Effects on the ECOC contributions to the reputation of Maribor & \\
Time period & 13.01 & .000 & .003 \\
Geographical area & 34.75 & .000 & .007 \\
Time period $\times$ geographical area & 1.02 & .312 & .000 \\
Effects on the ECOC contributions to the reputation of Slovenia & \\
Time period & .49 & .484 & .000 \\
Geographical area & .88 & .348 & .000 \\
Time period $\times$ geographical area & .37 & .541 & .000 \\
Effects on community pride in the ECOC being held in Maribor & \\
Time period & 278.31 & .000 & .055 \\
Geographical area & 11.14 & .001 & .002 \\
Time period $\times$ Geographical area & 89.27 & .000 & .018 \\
\hline
\end{tabular}

\section{Results}

\subsection{The Effect of the Time Period and Geographical Area on Opinions About the ECOC Contributions to Community Reputation and Community Pride}

We conducted two-factor between-groups ANOVA in order to assess the effect of the time period (the first and the second half-year) and geographical area (Slovenia and Maribor) on (a) ECOC contributions to the reputation of Maribor, (b) ECOC contributions to the reputation of Slovenia, and (c) Community pride in the ECOC being held in Maribor. Table 2 shows the rounded values for the mean and Standard Deviation values, while Table 3 further summarises results of the analysis for above-mentioned effects where degrees of freedom are $d f(1,4787)$. Results are described in detail in what follows.

Firstly, as one can see from Table 3, we found no interaction between the effects of time period and geographical area on respondents' opinion about the ECOC contribution to the reputation of Maribor. However, we found a statistically significant effect of the time period on respondents' opinion about the ECOC contribution to the reputation of Maribor, indicating that it can be compared to what extent respondents agreed in different time periods that the ECOC contributed to the reputation of Maribor. Accordingly, in the second 
time period, the score for both people from Maribor and Slovenia was statistically significantly higher than the first time period. Moreover, Table 3 shows that there was a statistically significant effect of the geographical area on respondents' opinion about the ECOC contribution to the reputation of Maribor. According to Table 2, it indicates that people from Maribor demonstrated statistically significantly higher scores in their opinions about the ECOC contribution to the reputation of Maribor than people from Slovenia.

Secondly, we found no interaction between the effects of time period and the geographical area on respondents' opinions about the ECOC contribution to the reputation of Slovenia (see Table 3). Likewise, we did not find effect either of time period or the geographical area on the same opinion.

Thirdly, Table 3 shows results of the analysis for effects on community pride in the ECOC being held in Maribor. A statistically significant interaction was found between the effects of time period and geographical area on community pride regarding the ECOC being held in Maribor. As can be seen both from Table 2 and Fig. 1, this result indicates that community pride in the second time period improved in Slovenes statistically significantly more than in people from Maribor, when compared to community pride in the first time period. In the first time period, Slovenes were less proud of ECOC being held in Maribor than people from Maribor. What changed in the second time period is that Slovenes were statistically significantly more proud of the event than people from Maribor.

Moreover, we found a statistically significant effect of time period on community pride regarding the ECOC held in Maribor (see Table 3), which indicates that community pride was, in the first time period, statistically significantly worse than in the second time period. Likewise, we found a statistically significant effect of the geographical area on community pride, showing that the Slovenes demonstrated statistically significantly lower scores in community pride than people from Maribor (see Table 2).

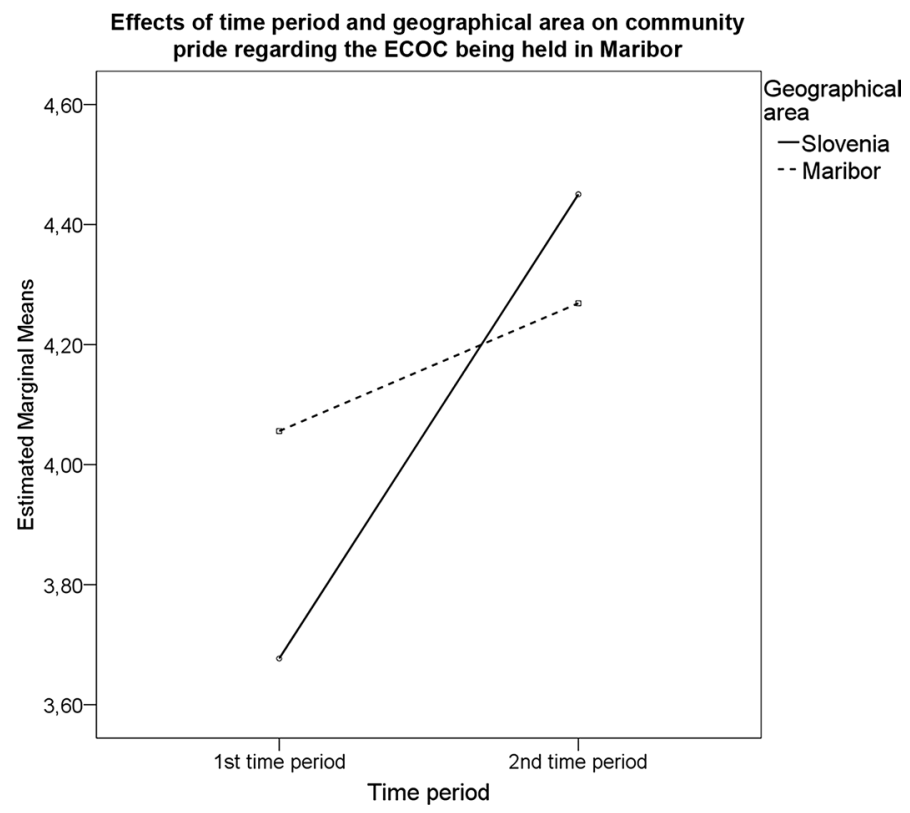

Fig. 1 Community pride regarding the ECOC being held in Maribor according to time period and geographical area 


\subsection{The Effect of ECOC Participation and Geographical Area on Opinions About the ECOC Contributions to Community Reputation and Community Pride}

We further examined the effects of participation at ECOC events (passive and active participation) and geographical area (Slovenia and Maribor) on (a) ECOC contributions to the reputation of Maribor, (b) ECOC contributions to the reputation of Slovenia, and (c) Community pride regarding the ECOC being held in Maribor. Concerning participation, only those who indicated that they participated at ECOC events, passively or actively, were included. Table 4 summarises results of the analysis for the above-mentioned effects where degrees of freedom are $d f(1,4635)$.

Firstly, the results revealed a statistically significant interaction between the effects of participation and geographical area on ECOC contributions to the reputation of Maribor (see Table 4). As can be seen in Fig. 2, it indicates that Slovenes who participated actively in ECOC events reported statistically significantly higher scores in their ECOC contribution to the reputation of Maribor $(M=4.08, S D=.94)$ compared to people from Maribor who participated actively $(M=4.02, S D=1.06)$. In contrast, people from Maribor who participated actively in ECOC events, reported statistically significantly higher scores $(M=3.86, S D=1.07)$ than Slovenes who participated passively $(M=3.70, S D=1.04)$.

Secondly, as one can see from Table 4, we found no interaction of participation and geographical area on the ECOC contribution to the reputation of Slovenia. Further results, however, showed that there was a statistically significant effect of participation on the ECOC contribution to the reputation of Slovenia. It indicates that those who participated passively in ECOC events, reported statistically significantly lower mean scores in their opinion about the ECOC contribution to the reputation of Slovenia $(M=3.56, S D=1.15)$ than those who participated more actively $(M=3.65, S D=1.13)$. Similarly, unlike the finding presented in Table 3, we found among those who at least participated at ECOC events either passively or actively, a statistically significant effect of geographical area on the ECOC contribution to the reputation of Slovenia (see Table 4). Those who come from Maribor reported statistically significantly lower scores $(M=3.56, S D=1.19)$ than Slovenes $(M=3.60, S D=1.10)$.

Thirdly, we did not find an interaction for participation and geographical area on community pride (see Table 4). Likewise, we did not find effect of geographical area on community

Table 4 Results of effects of participation at ECOC events and geographical area on the ECOC contribution to the reputation of Maribor, Slovenia and community pride

\begin{tabular}{lccc}
\hline & $F$ & $p$ & $\eta_{p}^{2}$ \\
\hline Effects on the ECOC contributions to the reputation of Maribor & \\
Participation & 38.61 & .000 & .008 \\
Geographical area & 1.26 & .262 & .002 \\
Participation $\times$ geographical area & 7.05 & .008 & .002 \\
Effects on the ECOC contributions to the reputation of Slovenia & \\
Participation & 8.12 & .004 & .002 \\
Geographical area & 4.18 & .041 & .001 \\
Participation $\times$ geographical area & .639 & .424 & .000 \\
Effects on community pride in the ECOC being held in Maribor & \\
Participation & 8.54 & .003 & .002 \\
Geographical area & 2.82 & .093 & .000 \\
Participation $\times$ geographical area & .685 & .408 & .000 \\
\hline
\end{tabular}




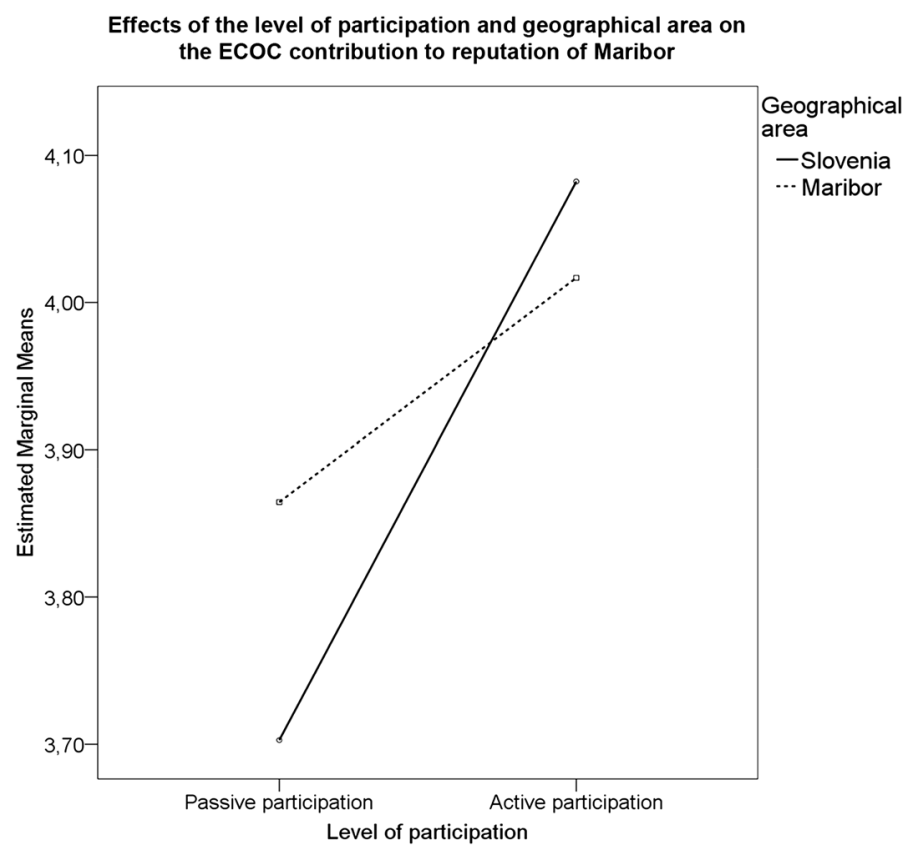

Fig. 2 The ECOC contribution to the reputation of Maribor according to the level of participation and geographical area

pride. Participation was, however, found to have a statistically significant effect on community pride. It indicates that those who participated more actively at the ECOC events showed statistically significantly higher scores in community pride $(M=4.24, S D=1.03)$ compared to those who participated more passively $(M=4.09, S D=1.04)$.

Further on, we found no interaction between the effects of time period, geographical area and level of participation on the ECOC contributions to the reputation of Maribor and Slovenia, as well as community pride regarding the ECOC being held in Maribor.

\subsection{The Effect of Geographical Area and Various Demographic Characteristics on Community Pride}

We employed multiple regression analyses to investigate whether community pride can be predicted by particular socio-demographic characteristics, such as gender, age and education, and geographical area. We also employed interaction effects in the analyses to investigate the community pride in order to see which demographic subgroups of the population were affected more or less strongly by geographical area.

Table 5 shows four different estimations, which can be understood as separate regression models which explain the relative contribution of each of the predictors (e.g. geographical area, gender, age and education) to the total variance explained (overall fit of the regression model). In Estimation 1, we only included the main effects of geographical area, gender, age and education on community pride, while, in estimations $2-4$, we included the above-mentioned main effects, along with the interaction effects of geographical area with the remaining three socio-demographical variables, respectively. 
Table 5 Multiple regression analysis of socio-demographic predictors of community pride regarding ECOC being held in Maribor, along with interaction effects of geographical area with gender, age and education of respondents

\begin{tabular}{|c|c|c|c|c|c|c|c|c|}
\hline & $\beta$ & $t$ & $p$ & $F$ & $d f$ & $p$ & $R^{2}$ & $\operatorname{adj.} R^{2}$ \\
\hline \multicolumn{9}{|l|}{ Estimation 1} \\
\hline Overall model & & & & 18.88 & 4 & .000 & .016 & .015 \\
\hline Geographical area & .066 & -4.567 & .000 & & & & & \\
\hline Gender & .081 & -5.638 & .000 & & & & & \\
\hline Age & .055 & -3.752 & .000 & & & & & \\
\hline Education & -.029 & 1.999 & .046 & & & & & \\
\hline \multicolumn{9}{|l|}{ Estimation 2} \\
\hline Overall model & & & & 15.27 & 5 & .000 & .016 & .015 \\
\hline Geographical area & -.025 & -.539 & .590 & & & & & \\
\hline Gender & -.069 & -3.566 & .000 & & & & & \\
\hline Age & -.054 & -3.712 & .000 & & & & & \\
\hline Education & .030 & 2.022 & .043 & & & & & \\
\hline Geographical area $\times$ gender & .044 & .922 & .356 & & & & & \\
\hline \multicolumn{9}{|l|}{ Estimation 3} \\
\hline Overall model & & & & 18.74 & 5 & .000 & .019 & .018 \\
\hline Geographical area & .104 & 2.442 & .015 & & & & & \\
\hline Gender & -.079 & -5.493 & .000 & & & & & \\
\hline Age & .002 & .076 & .939 & & & & & \\
\hline Education & .030 & 2.077 & .038 & & & & & \\
\hline Geographical area $\times$ age & .187 & 4.236 & .000 & & & & & \\
\hline \multicolumn{9}{|l|}{ Estimation 4} \\
\hline Overall model & & & & 21.01 & 5 & .000 & .021 & .020 \\
\hline Geographical area & -.270 & -6.665 & .000 & & & & & \\
\hline Gender & -.082 & -5.744 & .000 & & & & & \\
\hline Age & -.055 & -3.790 & .000 & & & & & \\
\hline Education & -.039 & -2.006 & .045 & & & & & \\
\hline Geographical area $\times$ education & -.233 & -5.394 & .000 & & & & & \\
\hline
\end{tabular}

Results of multiple regression analyses revealed that geographical area, gender, age and education are statistically significant predictors of community pride (see Estimation 1 in Table 5). It indicates that people from Maribor are more proud of the ECOC being held in Maribor compared to Slovenes. Moreover, women are more proud than men, and older people more so than younger ones. More educated people are, however, less proud of the ECOC being held in Maribor than those with lower levels of education.

According to Table 5, in Estimation 2, we found no interaction between the variables geographical area and gender. It indicates that the impact of geographical area on community pride does not depend on gender. The interaction of geographical area and age is statistically significant and negative (Estimation 3). This effect suggests that older people from Maribor are less proud of the ECOC being held in Maribor compared to younger Slovenes, while this suggests that older people are less proud. The interaction of geographical area and education is negative and statistically significant (Estimation 4). It indicates that the Slovenes with a lower level of education tend to have a higher 
level of community pride than those who come from Maribor and have a higher level of education.

\section{Discussion}

In this study, we aimed to examine the effects of the duration of the ECOC and geographical area on community reputation and community pride. Moreover, our aim was to investigate whether both citizens' participation at ECOC events and geographical area concurrently affect community reputation and community pride. The latter was examined further in terms of discovering effects of socio-demographic characteristics.

The findings suggest primarily that people from Maribor, the ECOC holder city, were statistically significantly more proud of the event during half of the ECOC year than Slovenes from other parts of the country, which changed at the end of the ECOC year, when Slovenes were statistically significantly more proud of the event than people from the ECOC holder city. This finding is similar to findings by Richards and Wilson (2004), who found that Dutch tourists from other parts of the country tended to score Rotterdam, the ECOC holder in 2001, higher than Rotterdammers in terms of 'its physical features and appraisive-evaluative aspects, such as 'multicultural', 'international' and 'dynamic' (Richards and Wilson 2004: 1941). Likewise, our findings reflect the proposition of the previous study (Liu 2014), where the residents of Liverpool city centre as the ECOC holder were "least likely to agree that their neighbourhood has a strong sense of community" (pp. 992-993).

In the Slovenian context, the above-mentioned finding can be understood, due to the relatively small Slovenian population and geographical area of the country. Citizens from other parts of the country may, thus, identify with the ECOC holder city to a greater extent than people in larger nations. Likewise, they may recognise the importance of the event for the whole country more strongly, whereas an understanding of the ECOC as a European brand and the pride of Slovenes to be part of the EU can be felt.

For instance, with respect to Slovenian history, younger generations may be more connected to the EU compared to older generations and may, thus, perceive themselves more as citizens of Europe than citizens of their own Nation State. In contrast, the attitude of older generations could be understood in the sense of their historical attachment to the geographically more extensive, but now defunct, Yugoslavia, as they may still feel nostalgic about their identification with that State.

Moreover, the reason for the shift in pride which occurred in the second half of the ECOC year, so that Slovenes were more proud of the ECOC holder city than the citizens of the city, could be understood as follows: Based on the above-mentioned feelings regarding mental attachment to the former State of Yugoslavia, the perception of the EU may not be as high as expected, which then increased with the economic crisis, which mostly affected Maribor and its surroundings in Slovenia. Even more, in the second part of the ECOC year, more people from other parts of the country participated in the events and, therefore, they were more aware of the ECOC in Maribor. The strategy of the organisers of the ECOC event was to attract people from other parts of Slovenia to attend ECOC in Maribor. One of the reasons is that, in 2011, the results of the audience research showed that around $60 \%$ of inhabitants of the Slovenian capital Ljubljana had never even visited Maribor. The awareness and the participation of events could, thus, contribute to higher scoring of ECOC. 
A similar explanation may apply to the next finding of our study, which suggests that Slovenes who participated actively in ECOC events recognised better the community reputation of Maribor for its ECOC designation than people from Maribor who also participated actively. This effect is likely to be understood through characteristics of the ECOC programme held in Maribor and its influence on citizens.

For instance, the programme of the public institute Maribor 2012 offered a wide range of events on a digital level, such as the project "Life touch", where web activities were presented as well. This could be a reason why web visitors also perceived themselves to be supporters or even visitors of the ECOC. What is more, some co-productions of artistic events took place not only in Maribor, but also in some other cities, which helps to explain why the ECOC had the potential of being perceived as a national project. Furthermore, as a novelty, Maribor was the first ECOC holder city in the history of these events to put the project on Instagram, even though the creation of this social networking service dates back to 2010 (Instagram 2015).

When estimating the effects of socio-demographic characteristics on community pride, either in Maribor or Slovenia, statistically significant interactions were found between geographical area on the one hand, as well as age and education on the other hand. The effect of education and geographical area on community pride, resulting in Slovenes with a lower level of education being inclined to have a higher level of community pride than those who come from Maribor and have a higher level of education, could also fall to the nature of the ECOC events. For instance, in contrast to previous ECOC events, in Maribor only a few 'high arts' events were held. The majority of the programme was instead addressed to a broader public, and many of the events were entrance fee free. Likewise, smaller parts of the project, such as urban gardening, art camps in park, activities for the disabled and minorities, open space concerts, were designed to be accessible to the public with smaller incomes as well.

Our finding on the effect of education on community pride intriguingly complements the findings of previous studies (Steiner et al. 2015; Richards and Wilson 2004), where it was found that more highly educated individuals are more inclined to attend ECOC events more often and actually also participate in ECOC events more frequently than individuals with lower levels of education (e.g. Garcia et al. 2010; Garcia and Cox 2013; Richards and Wilson 2004; Richards 2000). While these studies focused mainly on participation, our findings reveal wider impacts of ECOC events both in terms of education and geographical area, resulting in a consequence of community pride.

Further on, our findings complement the findings of previous studies in the methodological approach. For instance, while Richards and Wilson (2004) included in their study only tourists who actually attended the ECOC events in Rotterdam, we measured effects not only among active visitors, but also among passive visitors, i.e. those who were at least familiar with the ECOC by gathering information from media or other means of information. As already explained, we also included participants who were affected by intensive media coverage, not only in traditional media, but also in new social media. All the above-mentioned points were applied on a sample of citizens not only from Maribor, but also from the whole country.

\section{Conclusions}

With the present study in mind, we aimed to make a scientific contribution to the examination of community reputation and community pride with the example of the ECOC experience in Maribor, the ECOC holder in 2012. Previously conducted and similar studies concerning the ECOC focused on cultural impact, such as city image, identity 
and discourses of European identity, disregarding the concurrent effect of time during the ECOC year, the visitors' geographical origin, or even their level of participation at ECOC events on community reputation and community pride. Thus, this gap was the focus of our study presented in this paper.

One of the intriguing and significant findings of the current study is a higher reputation score with regard to Slovenes who participated actively in ECOC events, when compared to people from Maribor who reported the same level of participation. Thus, the findings underline the fact that it is important for the organisers of ECOC events to be aware of the wide impact of the ECOC on public opinion about the importance of these events for the reputation of a city and a country, as well as on feelings of pride. Moreover, the ECOC is a huge cultural project, where different audiences should be addressed. When organisers tend to get the publicity with events for mass audiences, they should also include the elitist events (for smaller segments of the audiences). The economic situation in Slovenia dictates that most of the events should be free of charge, but this also inhabits the meaning that "high culture" should not be free of charge. The quality of the events could be connected/perceived together with the material value that users are prepared to pay for.

The wider implications of the study can be seen in suggestions to organisers of ECOC events to be aware of existing differences in citizens' perception of these events and, consequently, of experienced reputation and pride. As a result, an emphasis should be given not only on the performance of ECOC events, but also on the representation of ECOC events in the media. Moreover, it should be considered that not only active, but also passive participation, should be taken into account when researching the impact of ECOC. Accordingly, taking into account the wider implication and perception of the ECOC project, the relation to wider social context in the city, in the country and in Europe should be taken into consideration. The political and economic context of Europe and its representation in the media can be also relevant for the perception of the European projects as ECOC.

As already mentioned in the Methodology section, the current study is limited to the self-reporting used in the study and the data collection method not being fully accessible to the wider public, such as people with no telephone land line and those with hearing loss, even though ECOC in Maribor organised a wide range of the programmes for this social group. However, ECOC is one of the few projects that try to connect different national communities with enabling any of the subjects to express their own identity. With the criterion "European dimension" that is relevant in the selection process for the ECOC title, cities have enormous possibilities to find the creative and unique solutions to common European problems. Such events may also help overcome intercultural differences among visitors and/or citizens of a particular country, since a previous study (Klak and Martin 2003), has shown an example of students who organised cultural events that may help deepen attendees' intercultural appreciation in terms of shift on intercultural sensitivity in the predicted direction of greater openness to other cultures, e.g. greater engagement with cultural differences among event attendees.

Some issues have not yet been addressed, such as measuring the impact of media coverage and the type of ECOC events on community reputation and community pride, while considering time, geographical area and level of participation. Accordingly, research is needed to clarify whether a certain level of experienced pride and reputation depends on the representation of ECOC content or events in media compared to actual visits at ECOC events. 
Open Access This article is distributed under the terms of the Creative Commons Attribution 4.0 International License (http://creativecommons.org/licenses/by/4.0/), which permits unrestricted use, distribution, and reproduction in any medium, provided you give appropriate credit to the original author(s) and the source, provide a link to the Creative Commons license, and indicate if changes were made.

\section{References}

Aiello, G., \& Thurlow, C. (2006). Symbolic capitals: Visual discourse and intercultural exchange in the European capitals of culture scheme. Language and Intercultural Communication, 6(2), 148-162.

Allen, J., O’Toole, W., Mcdonnell, I., \& Harris, R. (2002). Festival and special event management. London: Wiley.

Aronowitz, S. (1992). The politics of identity: Class, culture and social movements. New York: Routledge, Chapman and Hall.

Bihagen, E., \& Katz-Gerro, T. (2000). Culture consumption in Sweden: The stability of gender differences. Poetics, 27(5-6), 327-349.

Boyle, S., Joham, C., \& Abdullah, A. (2010). A study of attendances to an international arts festival. In The 6th international conference on cultural policy research, Jyväskylä, Finland, 24-27 August (pp. 1-12). Finland: University of Jyväskylä.

Bromley, D. B. (2003). Psychological aspects of corporate identity, image and reputation. Corporate Reputation Review, 3(3), 240-252. https://doi.org/10.1057/palgrave.crr.1540117.

Corijn, E., \& Van Praet, S. (1994). Antwerp 93 in the Context of European Cultural Capitals: Art Policy as Politics. Brussels: Vrije Unversiteit Brussels.

Crow, D. (1994). My friends in low places: Building identity for place and community. Environment and Planning D: Society and Space, 12(4), 403-419.

Davies, T. (2012). The decade after: Copenhagen 1996. Bruges 2012 Conference-The Decade After: The Legacy of European Capitals of Culture, 22 May 2012, Bruges, Belguim.

Debevc, M., Milošević, D., \& Kožuh, I. (2015). A comparison of comprehension processes in sign language interpreter videos with or without captions. PLoS ONE, 10(5), 1-10.

Delamere, T. A., Wankel, L. M., \& Hinch, T. (2001). Development of a scale to measure resident attitudes towards the social impacts of community festivals. Part 1: Item generation and purification of the measure. Event Management: An International Journal, 7(1), 11-24.

Firebaugh, G. (1997). Analyzing repeated surveys. Thousand Oaks, CA: Sage.

Fredline, E., \& Faulkner, B. (1998). Resident reactions to a major tourist event: The Gold Coast Indy Car Race. Festival Management and Event Tourism, 5(4), 185-205.

Garcia, B. (2003). The cities and culture project. Centre for Cultural Policy Research, University of Glasgow.

Garcia, B. (2005). Deconstructing the city of culture: The long-term cultural legacies of Glasgow 1990. Urban Studies, 42(5-6), 841-868.

Garcia, B. (2010). Media impact assessment (Part II). Evolving press and broadcast narratives on Liverpool from 1996 to 2009. Impacts 08, Liverpool.

Garcia, B., \& Cox, T. (2013). European capitals of culture: Success strategies and long-term effects. Policy Department B: Structural and Cohesion Policies. European Union. Retrieved from www. europarl.europa.eu/studies.

Garcia, B., Melville, R., Cox, T. (2010). Creating an impact: Liverpool's experience as European Capital of Culture. Impacts 08, Liverpool.

Grieve, J., \& Sherry, E. (2012). Community benefits of major sport facilities: The Darebin International Sports Centre. Sport Management Review, 15, 218-229.

Hall, C. M. (1992). Hallmark tourist events. London: Belhaven Press.

Hudec, O., \& Džzupka, P. (2014). Culture-led regeneration through the young generation: Košice as the European Capital of Culture. European Urban and Regional Studies, 1-8.

IBM SPSS for Windows 21.0 [Computer software]. (2018). Chicago, IL: SPSS Inc.

Instagram. About us. Available at: https://instagram.com/about/us/. Accessed 29 July 2015.

Kearns, A., \& Forrest, R. (2000). Social cohesion and multilevel urban governance. Urban Studies, $37(5 / 6), 995-1017$

Klak, T., \& Martin, P. (2003). Do university-sponsored international cultural events help students to appreciate 'difference'? International Journal of Intercultural Relations, 27, 445-465.

Laerd Statistics. (2015a). Multiple regression analysis using SPSS statistics. Statistical tutorials and software guides. Retrieved from https://statistics.laerd.com/. 
Laerd Statistics. (2015b). Two-way ANOVA in SPSS statistics. Statistical tutorials and software guides. Retrieved from https://statistics.laerd.com/.

Lähdesmäki, T. (2012). Celebration of locality, regionality, national culture or Europeanness? Notions on areabased identities in Pécs 2010 culture in/and crisis. In: Proceedings of the 4th annual conference of the university network of the European capitals of culture (ed. W. Cloudenys), Antwerp, 27-28 October 2011, UNeECC Forum (Vol. 4). Pécs: University Network of the European Capitals of Culture.

Lähdesmäki, T. (2014). Discourses of Europeanness in the reception of the European Capital of Culture events: The case of Pécs 2010. European Urban and Regional Studies, 21(2), 191-205.

Lassur, S., Tafel-Viia, K., Summatavet, K., \& Terk, E. (2010). Intertwining of drivers in formation of new policy focus: Case of creative industries in Tallinn. Nordic Journal of Cultural Policy, 1(13), 59-86.

Liu, Y. D. (2014). Socio-cultural impacts of major event: Evidence from the 2008 European Capital of Culture, Liverpool. Social Indicators Research, 115, 983-998.

Liu, Y. D. (2017a). Event and community development: Planning legacy for the 2008 European Capital of Culture, Liverpool. Urban Science, 1(4), 39.

Liu, Y. D. (2017b). Quality of life as event legacy: An evaluation of Liverpool as the 2008 European Capital of Culture. Applied Research in Quality of Life, 12, 653-670.

Luxembourg and Greater region 2007. (2008). Final report. Luxembourg 2007.

Manzo, C. L., \& Perkins, D. D. (2006). Finding common ground: The importance of place attachment to community participation and planning. Journal of Planning Literature, 20(4), 335-350.

Mittag, J. (2008). Die Idee der Kulturhauptstadt Europas. Anfänge, Ausgestaltung und Auswirkungen europäischer Kulturpolitik [The idea of the European Capital of Culture. Beginnings, Arrangements and Impacts]. Essen: Klartext.

Palmer, R. (2004). European cities and capitals of culture. Study Prepared for the European Commission Part I. Brussels: Palmer-Rae Associates, International Cultural Advisors.

Palmer/Rae Associates. (2004). European cities and capitals of culture-City reports, Part II. Brussels: Palmer/Rae.

Palonen, E. (2010). Multi-level cultural policy and politics of the European capitals of culture. The Nordic Journal of Cultural Policy, 13(1), 87-108.

Pretty, G. H., Chipuer, H., \& Bramston, P. (2003). Sense of place amongst adolescents and adults in two rural Australian towns: The discriminating features of place attachment, sense of community and place dependence in relation to place identity. Journal of Environmental Psychology, 23(3), 273-287.

Richards, G. (2000). The European cultural capital event: Strategic weapon in the cultural arms race? Cultural Policy, 6(2), 159-181.

Richards, G., \& Wilson, J. (2004). The impact of cultural events on city image: Rotterdam, cultural capital of Europe 2001. Urban Studies, 41(10), 1931-1951.

Seaman, B. (2006). Empirical studies of demand for the performing arts. In V. Ginsburgh \& D. Throsby (Eds.), Handbook of the economics of art and culture (pp. 415-472). Amsterdam: North-Holland Publishing.

Stafford, M. R., \& Tripp, C. (2000). Age, income, and gender: Demographic determinants of community theatre patronage. Journal of Nonprofit and Public Sector Marketing, 8(2), $29-43$.

Statistični urad Republike Slovenije [Statistical Office of the Republic of Slovenia]. (2014). Največja naselja po številu prebivalcev [The largest settlements by the number of the population]. Retrieved from http:// www.stat.si/KrajevnaImena/pregledi_naselja_najvecja_prebivalci.asp?tlist=off\&txtIme=MARIB OR\&selNacin $=$ celo\&selTip $=$ naselja $\& I D=2620$.

Statistični urad Republike Slovenije [Statistical Office of the Republic of Slovenia]. (2015). Število in sestava prebivalstva [The number and the structure of the population]. Retrieved from http://www.stat.si/ StatWeb/pregled-podrocja?id=104\&headerbar $=15$.

Steiner, L., Frey, B., \& Hotz, S. (2015). European capitals of culture and life satisfaction. Urban Studies, 52(2), 374-394.

Turku 2011. (2010). Turku 2011 programme. Turku 2011.

Turku 2011 Foundation. (2012). European capital of culture Turku 2011. Final report of the Turku 2011 Foundation about the realisation of the European Capital of Culture Year. Turku 2011 Foundation.

Universidade do Minho. (2013). Guimarães 2012: Capital Europeia da Cultura Impactos Económicos e Sociais. Relatorio Executivo, http://www.gepac.gov.pt/gepac-dsepac/estudos-e-estatisticas/estudos/05impactos-economicos-e-sociais-da-guimaraes-2012-capital-europeia-da-cultura-relatorio-executivouniversidade-do-minho-2013-pdf.aspx. Accessed 21 April 2018.

Weisberg, H. F., Haynes, A. A., \& Krosnick, J. A. (1995). Social group polarization in 1992. In H. F. Weisberg (Ed.), Democracy's Frast: Elebrons in America (pp. 241-249). Chatham, NJ: Chatham House. 
Žilič Fišer, S., \& Erjavec, K. (2017). The political impact of the European Capital of Culture: 'Maribor 2012 gave us the power to change the regime'. The International Journal of Cultural Policy, 23(5), 1-16. 